\title{
AN INTRODUCTION TO PROSPECTIVE MULTIPLE ATTRIBUTE DECISION MAKING (PMADM)
}

\author{
Sarfaraz HASHEMKHANI ZOLFANI ${ }^{\mathrm{a}}$, Reza MAKNOON ${ }^{\mathrm{a}}$, \\ Edmundas Kazimieras ZAVADSKAS ${ }^{\mathrm{b}}$
}

${ }^{a}$ Department of Management, Science and Technology, Technology Foresight Group, Amirkabir University of Technology (Tehran Polytechnic), P.O. Box 1585-4413, Tehran, Iran ${ }^{b}$ Research Institute of Smart Building Technologies, Vilnius Gediminas Technical University, Sauletekio al. 11, LT-10223 Vilnius, Lithuania

Received 4 November 2015; accepted 27 January 2016

\begin{abstract}
In recent years futures science has received a great deal of attention and has gained worldwide credibility in the science community as the science of tomorrows. The countless applications of futures studies in various fields have been a major breakthrough for mankind. Undoubtedly, decision making is one of the most significant aspects of shaping the future and an integral part of any credible future research. Multiple Criteria Decision Making (MCDM) in general and Multiple Attribute Decision Making in particular (MADM), are among the most remarkable subparts of the decision making process. The most recent model developed using the MADM method is the Dynamic MADM. The model does not specifically concentrate on the future actions and approaches and remains to be fully explored. This research presents a new concept and a new approach in the MADM field which is called the Prospective Multiple Attribute Decision Making (PMADM). The PMADM model can very well cover the DMADM concept but instead chooses to focus on future topics. The study also introduces two new approaches. The first research aims to elaborate the basis of this model and then evolves to deal with the future limiters as they potentially pop up and change the course of future actions. The new model based on future limiters is separated and categorized into two sections; one of which is looked upon without the probabilities rate and the other one with the probabilities rate. This approach is deemed priceless due to its major applicability in the ranking of the MADM methods such as: TOPSIS, VIKOR, COPRAS, ARAS, WASPAS and etc. Finally, a case study with the various applications of PMADM model in WASPAS methodology is put forth and illustrated.
\end{abstract}

Keywords: Prospective Multiple Attribute Decision Making (PMADM), decision making, future, MADM, limiters.

JEL Classification: C02, C44, C61.

Corresponding author Reza Maknoon

E-mail:rmaknoon@yahoo.com 


\section{Introduction}

Nowadays Multiple-Attribute Decision Making (MADM) method is considered to be an appropriate way of making decisions in different fields such as: economics, system engineering, logistics, society, energy, management science and etc. (Behzadian et al. 2010, 2012; Ishizaka, Labib 2011; Chen, Li 2011; Scott et al. 2012; Chai et al. 2013; Wang et al. 2013; Aguezzoul 2014; Mardani et al. 2015).

Most decisions regarding real-world problems occur dynamically. Both alternatives and criteria can be considered dynamic because situations can easily change and the final decision must be made with caution (Campanella, Ribeiro 2011).

In cases considered to be among the dynamic, time dependency plays an integral role and therefore should be considered as a vital topic in the decision making process. So far alternatives have not considered the dynamic during a certain time period. In fact situations are constantly changing which makes the decision making process about the alternatives pretty challenging. The preferences will also change most definitely as the time goes by and these changes must be taken into consideration. The importance of time dependency and its significance in real-world situations shall not be ignored either (Saaty 2007).

Such models of decision making have been utilized both in the past and in the current performance of alternatives called Dynamic Multi-Criteria Decision Making (DMCDM), because the time is considered in them (Campanella, Ribeiro 2011; Lin et al. 2008; Saaty 2007; Zulueta et al. 2013). DMCDM is focused on topics which are performed based on information at different time periods (Lin et al. 2008; Teng 2011; Xu 2008; Xu, Yager 2008; Yao 2010). The question of what will happen in decision making regarding future topics is still unclear in MADM field and hasn't attracted that much through scholars. There are numerous topics which should be considered in decision making when it comes to future issues.

In order to solve the problems more effectively in the past, in both the alternatives and the criteria the fix and decision were assumed to have occurred only once. Without a doubt the validity of decisions would be compromised and this matter which failed to consider that values could change over time and situations (Jassbi et al. 2014). Generally decision making and planning for future always is so hard and requires more attention. In decision making about future matters many issues can occur like changes in the alternatives, criteria, needs and values but which one is more important and should be considered right from the start? If we consider values, alternatives and criteria won't change that much but still some topics and actions may happen and effect on the decision-making process and priorities. These probable important actions and problems are called limiters in this research and model. Each of them or a combination between them can happen and affect the whole process.

This research presents a new MADM model in decision making about future and considers alternatives due to the existing limiters. This can be an appropriate contribution in MADM field and make that more helpful. Limiters classically consider based on experts' idea but other methodologies can be applied to this model. Scenarios can be considered as limiters but consider that the best alternative is without limiter then scenarios should have a negative perspective. Consider that limiters have been considered for alternatives 
and because of that they cannot be better than the assumption made in this step. In future researches the positive scenarios can be considered but the criteria should be changed as well. This new model in MADM about future situations calls Prospective Multiple Attribute Decision Making (PMADM) up until now and will focus on the future issues in MADM methodology. This new model is just an introduction in the PMADM field. To illustrate, more applications of PMADM model were applied in WASPAS methodology with a case study in Amirkabir University of Technology (Tehran, Iran).

\section{A brief literature on Multiple Attribute Decision Making (up to now)}

Three powerful review articles have been published since 2011 on MCDM field from first up to now (Zavadskas, Turskis 2011; Liou, Tzeng 2012; Zavadskas et al. 2014). As all researchers know MCDM and especially MADM as a multi-disciplinary methodology which is useful in decision making in different fields, this issue would possibly be one of the best advantages of this multi-disciplinary field. Zavadskas et al. (2014) have presented a category from applications of MCDM in different fields such as: Management, Economic, Civil Engineering, Geography, Environmental studies, Chemistry, Business, Planning, Computer science and etc. Then it can be concluded that MCDM is a worldwide accepted methodology across all fields.

MADM as a methodology officially has started since 1968 when SAW method introduced (MacCrimon 1968). Ever since that moment so many MADM methodologies have emerged up to now and BWM (Rezaei 2015) were the last ones to have been proposed. During this time period so many classic MADM methods developed such as: AHP (Saaty 1980), TOPSIS (Hwang, Yoon 1981), ELECTRE (Roy 1968), COPRAS (Zavadskas, Kaklauskas 1996), ARAS (Zavadskas, Turskis 2010), VIKOR (Opricovic 1998), SWARA (Keršulienė et al. 2010), WASPAS (Zavadskas et al. 2012), MACBETH (Bana e Costa, Vansnick 1994), FARE (Ginevicius 2011), PROMETHEE (Brans et al. 1984), MOORA (Brauers, Zavadskas 2006), MULTIMOORA (Brauers, Zavadskas 2010) and etc. All classic MADM methods have advantages in decision making process but these methodologies do not consider the dynamics in the time periods. Nowadays, decision making about future topics is more important in comparison with one decade ago and it seems methodologies should be expanded and tailored to this need. Generally MADM in one of best methodologies in all decision making fields and this would be an appropriate time for developing Prospective Multiple Attribute Decision Making (PMADM). PMADM is a new horizon in the decision making in general and class MADM that has ever been put forth.

\section{A brief literature on new trends in MADM towards future topics}

Ozernoy (1988) has presented a brief investigative approach on the application of MCDM methods in USSR in time period of 1971-1986. USSR previously applied MCDM methods in the science and technology issue and R\&D project selection. They have had a long-term perspective for selecting the big projects. This research was one of the first long term perspectives in the past. 
One of the first researches on dynamic decision making in MADM field was presented in 1998. In that research dynamic MADM described in a way that views such decisions with time and uncertainty factors considered distinctly. This research claimed that for different situations different results and outcomes will come about (Leong 1998).

Another one of the first main researches on MADM and future studies was presented in 2003 (Salo et al. 2003). In that research MADM applied in technology foresight field about decision making in $\mathrm{R} \& \mathrm{D}$ projects, but the presented article did not put forth any new methodology for this purpose. Moreover, the research just considered the probable future and made classic decisions based on MADM methods.

In 2008, Xu tried to consider the criteria's weight dynamically. His research proposed that importance of criteria in different time periods are different. Xu applied interval data for this purpose, but eventually did not present a special methodology to serve this purpose. Nevertheless the idea was a notable contribution to the field.

Another research on dynamic MADM is about using historical data and time series analysis which was presented in 2010 (Lou et al. 2010). The article did not specifically focus on the future, but prediction can be a good start to this end.

Campanella and Ribeiro (2011) investigated the classic methods of MADM and dynamic MADM. Research presented a learning system based on the MADM model and used historic data and past experiences in the model. The system which was presented in the research is applied in helicopter's control. In different instances, the system recorded the results and kept working in that way constantly.

Another progress in this area presented future scenarios and MADM methods (Trutnevyte et al. 2012). In this article visioning, scenario planning and MADM were applied altogether. Probable scenarios designed based on a clear vision in energy field and finally MADM framework was applied to analyze them.

Arms et al. (2012) separated strategies into two sections: static and dynamic. They emphasize the important issues that researchers should take into account. They proposed that each dynamic strategy should provide added value and also reduce or eradicate the possible risks in each scenario as it occurs in reality.

One of brilliant and primary idea in dynamic MADM presented in an article about green supplier selection (Zhang 2012). The author considered three distinct time periods for the decision making process and criteria. There isn't any special information about time periods but model had something new as an idea and alternatives were considered separately in each time period.

Durbach and Stewart (2012) concentrated on strategic topics and placed a greater emphasis on uncertainties in these kinds of topics. MADM framework is applied in this research but they also applied fuzzy numbers and scenarios for making their analysis. Prospective thinking can be identified from this research.

Foresight perspective is one of the other contributions made to this field. Hashemkhani Zolfani et al. (2013) added foresight perspective to the decision making process in MADM. The primary location for the possible site for the project at hand based on foresight perspective was chosen and the applicability was fully demonstrated in the presented research 
article. In fact locating sites based on a prospect perspective was the contribution the said study made using this new framework relating to this research, although the research presented a new hybrid MADM model but the new hybrid model can be categorized in the classic MADM framework.

Grey numbers was another way for considering time in a period. Wang et al. (2014) applied grey numbers in a classic MADM model for an investment case study.

Tadic et al. (2014) created a logical relationship between future scenarios and MADM methods. System logistic of Belgrade city was the case study of this research and authors evaluated future scenarios based on FAHP and FTOPSIS. Decision making process is established based on current situation but there isn't any direct relationship to future situation in the research.

Dynamic AHP (DAHP) presented for developing application of AHP and in general MADM (Gonzalez-Prida et al. 2014). In literature AHP was the first classic method which was considered to be developed to a dynamic framework. The model is developed based on previous experiences from the past and did not say anything from the future. As we can see in literature DMADM is related to time but future is not on it for sure.

Ondrus et al. (2014) is designed based on Salo et al. (2003) research article. This research is based on MADM model and technology foresight just as Salo et al. (2003). This research added computer calculation and visualizing to the previous framework. Also a specialized model designed to each expert can cooperating in decision making based on those criteria that select by own.

Jassbi et al. (2014) presented a new model in DMADM. Past, current situation and future are considered in the new model and undoubtedly this new model presented in the article has been a major contribution. Disadvantages of this research are the time limitation regarding the future. This model only can consider the near future since it is highly dependent on using predictions for for calculating and analysis. In the following sections, two new models will be presented based on the PMADM concept. PMADM can easily cover DMADM models because every bit of applicable data for decision making in the future is significant to its development, yet it is not limited solely to DMADM. PMADM is designed to make decisions about future topics while in DMADM future does not necessarily have to be taken into consideration.

\section{New PMADM models based on future limitations}

Multiple Attribute Decision Making (MADM) process can be used to make decisions about future topics just as with the current situations. Generally MADM does not put forth any special approach for making decisions regarding future issues. This new model which is based on the MADM framework has a new perspective and approach in making decision about future.

The new model considers future limiters in the evaluation process. Each limiter which can occur in the future and within the time period a topic is being explored can be considered in the process of decision making about a possible future scenario. Previously in 
MADM field limiters did not used to be checked out during the solving process, even though it is quite obvious that for decision making about future scenarios, different factors and events can influence the deciding factors in reality. As time goes by, the inability to consider such limiters in the MADM methods and presented models starts to feel more consequential than they used to, simply because these days decision making about future scenarios has been gaining much more ground and credibility in comparison to the past.

The process includes evaluating alternatives based on existing limiters. In evaluating alternatives based on each criterion, alternatives are explored based on limiters as they are investigated by different experts and their ideas. For each future limiter alternative or alternatives are examined separately. Nevertheless, the best scenario is still the same as the one made in the classic MADM models which suggests that there are not any limiters observed in the model.

This model can easily be added to the previous MADM methods such as: TOPSIS, VIKOR, COPRAS, ARAS, WASPAS and etc. This is a merit of this new model because the inputs are identical to their original models. Inputs in evaluating alternatives based on criteria can be calculated with average of different scenarios for each alternative and criterion.

The nature of MADM models is expert based and this matter is so important in developing this field in decision making about future issues. This model isn't separate from this vital issue and alternatives in different scenarios are calculated based on experts' ideas about impacts of limiters on alternatives in each criterion. This can be joining to other methodologies from different fields but MADM field needs a separate special framework.

Future limiters can be considered from experts' perspective or other methodologies like Scenario Planning and Cross Impact Analysis can be helpful in identifying them. But this new originally model is designed based on experts' ideas.

Future limiters can be driving forces or any kind of actions that can be effective in a systematic decision making about something. Limiters can be considered in current position and experts can analyse them in the process of decision making but in decision making about an issue in the future, it's hard to say how much limiters can affect the actions and evaluations.

An important issue can be considered here is that the new model only shows limiters separately and this is not one of the limitations looked at on this research as they can simply be considered in decision making in different cases. These events could overlap, therefore adding more than two variables to the alternatives as a different limiter. This issue also can be another advantage of this research about new model. The new model can be considered in PMADM category and is shown in Table 1.

\section{New PMADM models based on future limitations and their probabilities}

In many cases the information available is not sufficient to make a solid decision. Future limitations will not be enough for decision making in many important cases. How should the limiters in the model be looked upon? This is the main question that will be addressed in this section. At first probabilities should be measured. This is a general model 
for PMADM and this research proposes that probabilities can be considered based on experts' idea. Other methodologies like Cross Impact Analysis can be applied in this section for measuring probabilities. Limiters with higher probabilities should have more effect in the model which is shown in the Tables 2 and 3.

This research proposes two different approaches in dealing with such predicaments. Table 2 exhibits the first approach in which probabilities are examined directly in accordance with the experts' ideas about evaluating alternatives based on limiters. This model preserves the priorities because evaluating will decrease the variables but not change the relationships between them and the alternatives will be valid. Authors consider this approach directly and called it the direct approach. Consider that options without limiter or limiters will no longer need any process in calculation; therefore deleted the corresponding cell can be removed from the tables.

Table 3 illustrates the indirect method in applying probabilities to the model. In this approach possible changes are studied separately and then re-examined with the probabilities included. Possible changes (P.C) should be compared to experts' evaluating of alternatives without limiters. P.C evaluating can be based on different measures and units. Generally, the way of thinking is vital in this section and differences in approaches are not regarded as important.

It should be noted that these models can be applied in ranking MADM methods like: TOPSIS, VIKOR, COPRAS, ARAS, WASPAS and etc. This is a general framework to develop MADM field in a new area which focuses mainly on the future studies.

Table 1. PMADM model based on future limitations

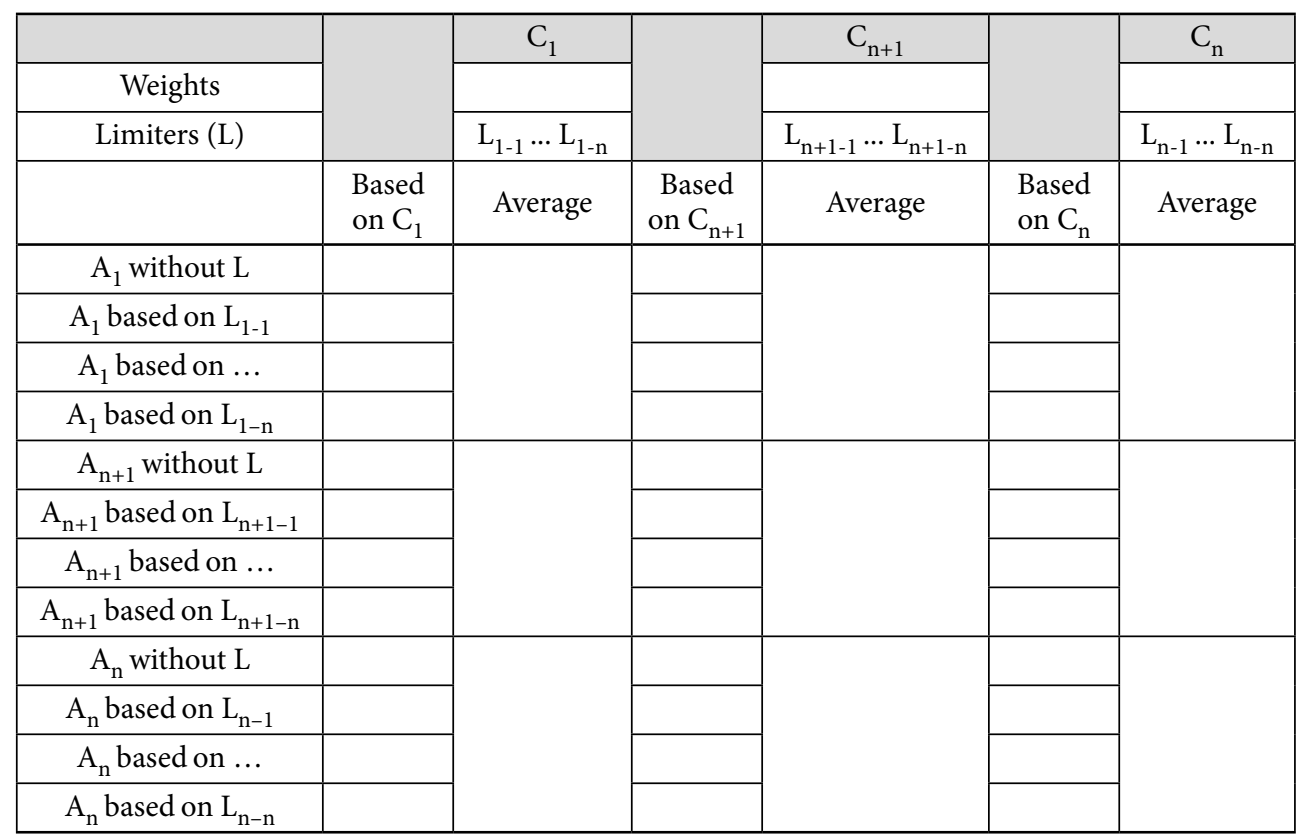




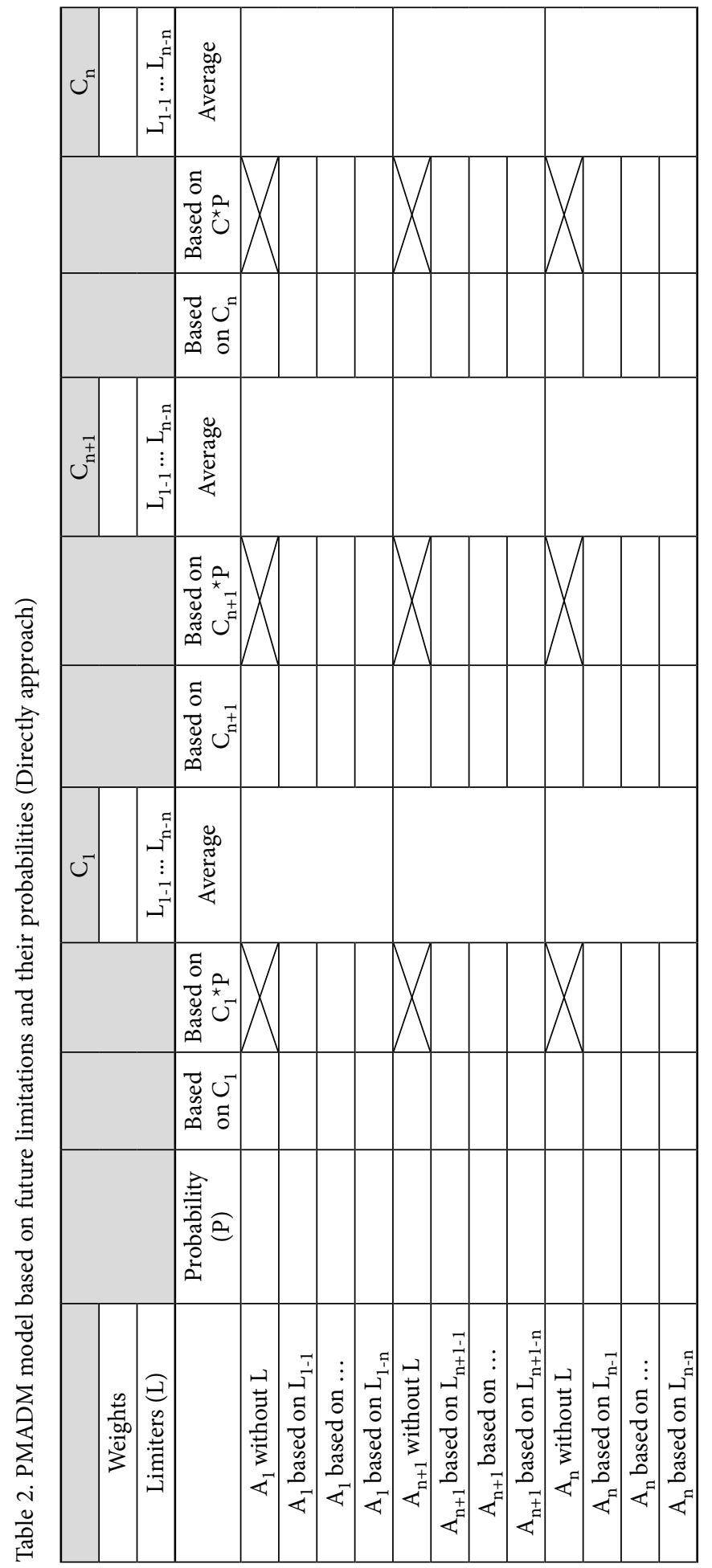




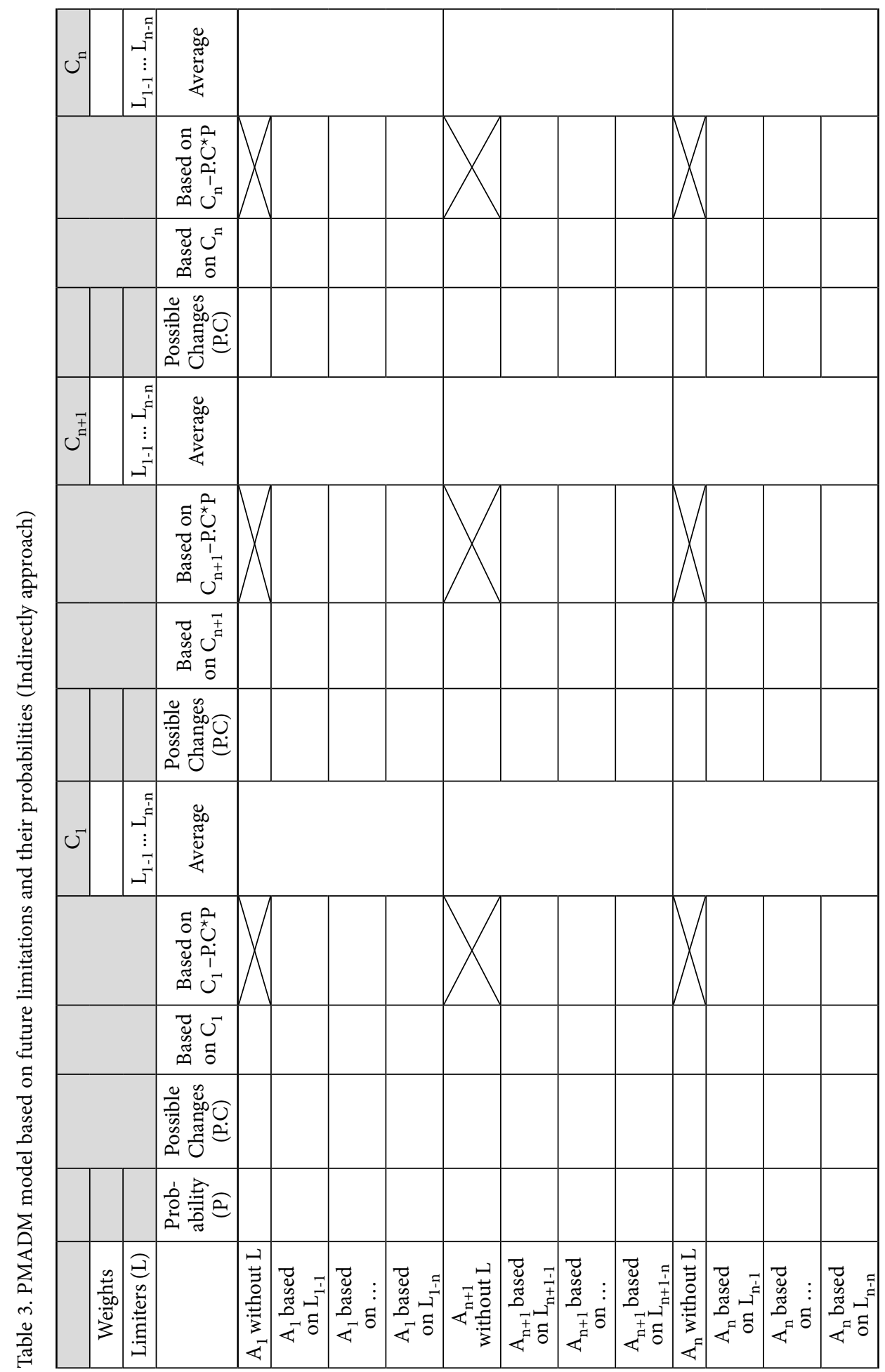




\section{Case study}

Amirkabir University of Technology, as a one of the most prestigious universities in Iran, put together a research team that started to do study and investigate the futures studies since 1995. In 2010 the futures studies research group was promoted to The Futures Studies Research Centre and has ever since been recruiting many post graduate students since 2010 and as of $2012 \mathrm{PhD}$ candidates to be a part of the team. The academic field for students define as a Technology Foresight program and includes many subfields. According to experiences that university got different fields included in their researches. The university looks forward to the best choices to expand their research areas. In this section the most appropriate fields will be evaluating with applying new concept in a classic MADM methods.

Research fields are defined in four categories which can be seen as follow: 1. Sustainable future and Sustainable development, 2. Policy making and Decision science, 3. R\&D and High tech industries, 4 . Entrepreneurship and innovation systems. Consider that these categories are designed based on previous experiences of university and also research its research outputs. In categorizing as an alternative, members of technology foresight group of the university have cooperated.

Criteria for this evaluation are selected in a meeting of Amirkabir University of Technology's technology foresight group with the participation of all five senior members. Members are included three professors, one associate professor and one assistant professor. Main members are from different research fields in general but have experiences in future studies in practise in their career. The main criteria have considered for this case study through the meeting: $\mathrm{C}_{1}$ : Necessary needs in industries and business foundations, $\mathrm{C}_{2}$ : Possibility of attract governmental and public sections participation, $\mathrm{C}_{3}$ : Coordination to university's interests and its vision, $\mathrm{C}_{4}$ : Coordination rate to members' research fields, $\mathrm{C}_{5}$ : Innovation level of researches (Ability).

Technology foresight group is believed to have directed its future career (next 15 years ahead) based on a suitable decision. The decision making model for group is designed multi-criteria and for evaluating PMADM model, this part of research is applied.

Technology foresight group have considered an equal weight for each criterion because they want to find an optimum way for all of criteria which are important for the group and the university. Then each criterion's weight is considered 0.2. Afterwards WASPAS methodology is selected for evaluating alternatives which is introduced in the previous section. WASPAS is introduced by Zavadskas et al. (2012) and has been developing since then in hybrid models in different studies. In this section PMADM is applied in WASPAS methodology and a new version of PWASPAS is presented. Consider that PWASPAS can be developed more in future due to needs and applications. At first step in PWASPAS decision making matrix is established in Table 4.

An important issue that should be considered is effects of limiters in evaluating. When limiters do not have any influence on alternative in comparison with a certain criterion, the evaluating doesn't change at all and will be as same as evaluating without limiter effect. Other steps are as same as WASPAS classic methodology which is shown in five steps below: 


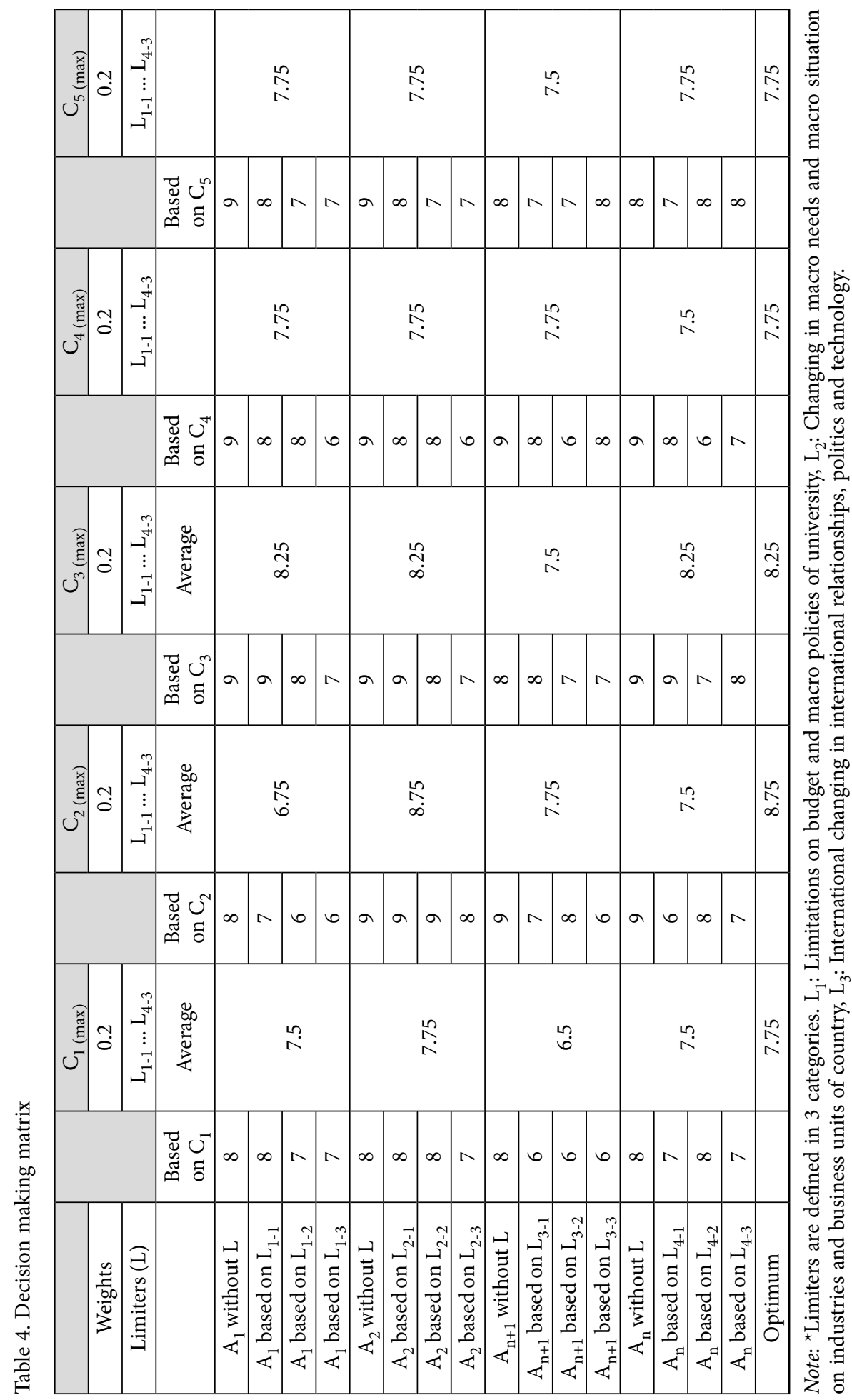


1. Normalized decision making matrix based on:

If opt value is $\max$

$$
\bar{x}_{i j}=\frac{x_{i j}}{\underset{i}{\operatorname{opt} x_{i j}}}, \text { where } i=\overline{1, m} ; j=\overline{1, n} \text {. }
$$

If opt value is min

$$
\bar{x}_{i j}=\frac{\operatorname{opt} x_{i j}}{x_{i j}}, \text { where } i=\overline{1, m} ; j=\overline{1, n} .
$$

2. Calculating WASPAS weighted and normalized decision making matrix for summarizing part:

$$
\overline{\bar{x}}_{i j, \mathrm{sum}}=\bar{x}_{i j} q_{j}, \text { where } i=\overline{1, m} ; j=\overline{1, n} .
$$

3. Calculating WASPAS weighted and normalized decision making matrix for multiplication part:

$$
\overline{\bar{x}}_{i j \text {,mult }}=x_{i j}^{-q_{j}} \text {, where } i=\overline{1, m} ; j=\overline{1, n} .
$$

4. Final calculating for evaluating and prioritizing alternatives based on:

$$
W P S_{i}=0.5 \sum_{j=1}^{n} \overline{\bar{X}} i j \text {, sum }+0.5 \prod_{j=1}^{n} \overline{\bar{X}} i j \text {, mult, where } i=\overline{1, m} ; j=\overline{1, n} \text {. }
$$

Table 6 is shown normalised and also weighted decision making matrix for the summarizing part which is calculated based on WASPAS methodology due to Table 5. Table 7 also is shown normalised and also weighted decision making matrix for multiplication part. Final results of PWASPAS methodology about evaluating alternatives is shown in Table 7.

Table 5. Normalized weighted decision making matrix for summarizing part

\begin{tabular}{cccccc}
\hline & $\mathrm{C}_{1}$ & $\mathrm{C}_{2}$ & $\mathrm{C}_{3}$ & $\mathrm{C}_{4}$ & $\mathrm{C}_{5}$ \\
\hline $\mathrm{A}_{1}$ & 0.194 & 0.154 & 0.200 & 0.200 & 0.200 \\
\hline $\mathrm{A}_{2}$ & 0.200 & 0.200 & 0.200 & 0.200 & 0.200 \\
\hline $\mathrm{A}_{3}$ & 0.168 & 0.177 & 0.182 & 0.200 & 0.194 \\
\hline $\mathrm{A}_{4}$ & 0.194 & 0.171 & 0.200 & 0.194 & 0.200 \\
\hline
\end{tabular}

Table 6. Normalized weighted decision making matrix for summarizing part multiplication part

\begin{tabular}{cccccc}
\hline & $\mathrm{C}_{1}$ & $\mathrm{C}_{2}$ & $\mathrm{C}_{3}$ & $\mathrm{C}_{4}$ & $\mathrm{C}_{5}$ \\
\hline $\mathrm{A}_{1}$ & 0.993 & 0.949 & 1.000 & 1.000 & 1.000 \\
\hline $\mathrm{A}_{2}$ & 1.000 & 1.000 & 1.000 & 1.000 & 1.000 \\
\hline $\mathrm{A}_{3}$ & 0.839 & 0.886 & 0.909 & 1.000 & 0.968 \\
\hline $\mathrm{A}_{4}$ & 0.973 & 0.872 & 1.000 & 0.968 & 1.000 \\
\hline
\end{tabular}

As result has shown policy making and decision science has good potential to be developed more in the group and university. Other fields' priority is obvious now and should be considered carefully in planning. Eventually, that was a real case study for evaluating this new model, PMADM, and applying that in classic MADM methods. 
Table 7. The results of WASPAS

\begin{tabular}{ccccc}
\hline & $0.5 \sum_{j=1}^{n} \overline{\bar{X}}$ ij, sum & $0.5 \prod_{j=1}^{n} \overline{\bar{X}} i j$, mult & WSP $_{\mathrm{i}}$ & Ranking \\
\hline $\mathrm{A}_{1}$ & 0.474 & 0.029 & 0.503 & 3 \\
\hline $\mathrm{A}_{2}$ & 0.500 & 0.031 & 0.531 & 1 \\
\hline $\mathrm{A}_{3}$ & 0.460 & 0.020 & 0.481 & 4 \\
\hline $\mathrm{A}_{4}$ & 0.479 & 0.026 & 0.505 & 2 \\
\hline
\end{tabular}

\section{Conclusions}

Each field has to develop due to needs and requirements and decision making is one of fields which pace of changes are much on it. MCDM in general and especially MADM as a part of it is one of notable parts of decision making. MADM as a field has only been known less than fifty years. At first, it did not develop much till 80 s but after that has been changing constantly according to needs and ideas. Decision making in general has been getting harder in comparison to the past because the world affairs used to be less complicated than what they are today. MADM field through these years has become more advanced in decision making because MADM has the capacity for incorporating new perspectives and new topics.

During these years MADM has developed to Dynamic MADM which views the time factor as an important parameter. Researches all around the world have concluded that decision making in different time periods should naturally bear different results. Scenarios change in different time periods which call for a more dynamic version of MADM to be developed. As the literature illustrated DMADM still needs to be developed in its concept. Jassbi et al. (2014) has so far been the most complete research on DMADM as they managed to explore the data from the past, the present and the future situations collectively. There are still some flaws in the research model but that is considerable. PMADM is totally concentrated on future topics as a core in decision making. Past, current and future information could be considered but only in future topics in general can be considerable.

Futures studies have developed in recent decades in different dimensions even as a separate field. Today futures studies and technology foresight are considered to be separate and a great number of methodologies have been developed in these fields. MADM field can be helpful in future studies in general because it needs to make an appropriate decision about future issues. Dynamic MADM could not fully cover future aspects and still needs to be improved. Also it needs a concept to consider all effective parameters even those that have not been identified yet in an MADM model.

In this research Prospective Multiple Attribute Decision Making (PMADM) introduced as a new approach for considering future topics in MADM model professionally. PMADM shouldn't be limited in current situation of MADM field and can be developed in all aspects of that and even consider and add new aspects to its concept. PMADM focuses deeply on future issues and can be considered as future studies methodology now or in near future. Current research just tried to present this new concept carefully and also present a new 
model based on this new concept. Furthermore, the case study about developing WASPAS method with PMADM concept can be helpful in describing better this new model and its applications.

As the first model for PMADM concept future limiters which are considered for the potential alternatives are added to the MADM framework. Each alternative is checked out separately through each limiter in each criterion. There isn't any particular limitation for the limiters because they can be considered through their different units and also can be viewed together or in a group of limiters all together. This is a general model for decision making when limiters will happen but other methodologies can be applied in this section such as: Scenarios, Cross Impact Analysis and other related future studies methodologies. Other outputs from other methodologies can be added to PMADM framework such as: Game Theory and System Dynamic.

In the next section some suggestions are presented which can direct probable future researches better. Without a doubt, PMADM can be a useful and powerful methodology in future studies and technology foresight fields, directly and in other multi-disciplinary fields and researches.

\section{Suggestions of future studies}

The main authors' suggestion can be followed:

- Considering future limiters with dynamic criteria's weights.

- Apply and develop scenarios in vital future topics as future limiters.

- Make a comparison between classic MADM methods with MADM methods with PMADM approach.

- Considering future in weighting criteria.

- Creating an MADM method based on PMADM approach from the base.

\section{References}

Aguezzoul, A. 2014. Third-party logistics selection problem: a literature review on criteria and methods, Omega 49: 69-87. http://dx.doi.org/10.1016/j.omega.2014.05.009

Arms, H.; Wiecher, M.; Kleiderman, V. 2012. Dynamic models for managing big decisions, Strategy \& Leadership 40(5): 39-46. http://dx.doi.org/10.1108/10878571211257177

Bana e Costa, C. A.; Vansnick, J. C. 1994. MACBETH: an interactive path towards the construction of cardinal value functions, International Transactions in Operational Research 1(4): 489-500. http://dx.doi.org/10.1016/0969-6016(94)90010-8

Behzadian, M.; Kazemzadeh, R. B.; Albadvi, A.; Aghdasi, M. 2010. PROMETHEE: a comprehensive literature review on methodologies and applications, European Journal of Operational Research 200(1): 198-215. http://dx.doi.org/10.1016/j.ejor.2009.01.021

Behzadian, M.; Khanmohammadi Otaghsara, S.; Yazdani, M.; Ignatius, J. 2012. A state-of the-art survey of TOPSIS applications, Expert Systems with Applications 39(17): 13051-13069.

http://dx.doi.org/10.1016/j.eswa.2012.05.056 
Brans, J. P.; Mareschal, B.; Vincke, P. 1984. PROMETHEE: a new family of outranking methods in multicriteria analysis, in J. P. Brans (Ed.). Operational Research '84 IFORS 84, 6-10 August 1984, Washington, D.C., USA. North Holland, 477-490.

Brauers, W. K. M.; Zavadskas, E. K. 2006. The MOORA method and its application to privatization in a transition economy, Control and Cybernetics 35(2): 443-468.

Brauers, W. K. M.; Zavadskas, E. K. 2010. Project management by MULTIMOORA as an instrument for transition economies, Technological and Economic Development of Economy 16(1): 5-24. http://dx.doi.org/10.3846/tede.2010.01

Campanella, G.; Ribeiro, R. A. 2011. A framework for dynamic multiple-criteria decision making, Decision Support Systems 52(1): 52-60. http://dx.doi.org/10.1016/j.dss.2011.05.003

Chai, J.; Liu, J. N. K.; Ngai, E. W. T. 2013. Application of decision-making techniques in supplier selection: a systematic review of literature, Expert Systems with Applications 40(10): 3872-3885. http://dx.doi.org/10.1016/j.eswa.2012.12.040

Chen, Y.; Li, B. 2011. Dynamic multi-attribute decision making model based on triangular intuitionistic fuzzy numbers, Scientia Iranica B18(2): 268-274. http://dx.doi.org/10.1016/j.scient.2011.03.022

Durbach, I. N.; Stewart, T. J. 2012. Modeling uncertainty in multi-criteria decision analysis, European Journal of Operational Research 223(1): 1-14. http://dx.doi.org/10.1016/j.ejor.2012.04.038

Ginevicius, R. 2011. A new determining method for the criteria weights in multi-criteria evaluation, International Journal of Information Technology \& Decision Making 10(6): 1067-1095. http://dx.doi.org/10.1142/S0219622011004713

Gonzalez-Prida, V.; Viveros, P.; Barbera, L.; Crespo Marquez, A. 2014. Dynamic analytic hierarchy process: AHP method adapted to a changing environment, Journal of Manufacturing Technology Management 24(4): 457-475.

Hashemkhani Zolfani, S.; Aghdaie, M. H.; Derakhti, A.; Zavadskas, E. K.; Morshed Varzandeh, M. H. 2013. Decision making on business issues with foresight perspective; an application of new hybrid MCDM model in shopping mall locating, Expert Systems with Applications 40(17): 7111-7121. http://dx.doi.org/10.1016/j.eswa.2013.06.040

Hwang, C. L.; Yoon, K. 1981. Multiple attribute decision making: a state of the art survey: Lecture Notes in Economics and Mathematical Systems, vol. 186. Berlin: Springer-Verlag. http://dx.doi.org/10.1007/978-3-642-48318-9

Ishizaka, A.; Labib, A. 2011. Review of the main developments in the analytic hierarchy process, Expert Systems with Applications 38(11): 14336-14345. http://dx.doi.org/10.1016/j.eswa.2011.04.143

Jassbi, J. J.; Ribeiro, R. A.; Varela, L. R. 2014. Dynamic MCDM with future knowledge for supplier selection, Journal of Decision Systems 23(3): 232-248. http://dx.doi.org/10.1080/12460125.2014.886850

Keršuliene, V.; Zavadskas, E. K.; Turskis, Z. 2010. Selection of rational dispute resolution method by applying new step-wise weight assessment ratio analysis (SWARA), Journal of Business Economics and Management 11(2): 243-258. http://dx.doi.org/10.3846/jbem.2010.12

Leong, T. Y. 1998. Multiple perspective dynamic decision making, Artificial Intelligence 105(1-2): 209261. http://dx.doi.org/10.1016/S0004-3702(98)00082-4

Lin, Y.; Lee, P.; Ting, H. 2008. Dynamic multi-attribute decision making model with grey number evaluations, Expert Systems with Applications 35(4): 1638-1644. http://dx.doi.org/10.1016/j.eswa.2007.08.064

Liou, J. J. H.; Tzeng, G. H. 2012. Comments on "MULTIPLE CRITERIA DECISION MAKING (MCDM) Methods in Economics: an overview", Technological and Economic Development of Economy 18(4): 672-695. http://dx.doi.org/10.3846/20294913.2012.753489

Lou, C.; Kou, G.; Peng, Y.; Ge, X. 2010. DMCDM: a dynamic multi criteria decision making model for sovereign credit default risk evaluation, 2nd International Conference on Software Engineering and Data Mining (SEDM), 23-25 June 2010, Chengdu, 489-494. 
MacCrimon, K. R. 1968. Decision marking among multiple-attribute alternatives: a survey and consolidated approach. RAND Memorandum, RM-4823-ARPA. The Rand Corporation, Santa Monica, Calif.

Mardani, A.; Jusoh, A.; Zavadskas, E. K. 2015. Fuzzy multiple criteria decision-making techniques and applications - two decades review from 1994 to 2014, Expert Systems with Applications 42(8): 4126-4148. http://dx.doi.org/10.1016/j.eswa.2015.01.003

Rezaei, J. 2015. Best-worst multi-criteria decision-making method, Omega 53: 49-57. http://dx.doi.org/10.1016/j.omega.2014.11.009

Roy, B. 1968. Classement et choix en presence de point de vue multiples: Le methode ELECTRE, Revue Francaise d'Informatique et de Recherche Operationnelle (RIRO) 8: 57-75.

Ondrus, J.; Bui, T.; Pigneur, Y. 2014. A foresight support system using MCDM methods, Group Decision and Negotiation 24(2): 333-358. http://dx.doi.org/10.1007/s10726-014-9392-8

Opricovic, S. 1998. Multiple criteria optimization of civil engineering systems. Faculty of Civil Engineering, Belgrade (in Serbian).

Ozernoy, V. M. 1988. Multiple criteria decision making in the USSR: a survey, Naval Research Logistics 35(6): 543-566. http://dx.doi.org/10.1002/1520-6750(198812)35:6<543::AID-NAV3220350604>3.0.CO;2-Q

Saaty, T. L. 1980. The analytical hierarchy process. New York: McGraw-Hill.

Saaty, T. L. 2007. Time dependent decision-making; dynamic priorities in the AHP/ANP: generalizing from points to functions and from real to complex variables, Mathematical and Computer Modelling 46(7-8): 860-891. http://dx.doi.org/10.1016/j.mcm.2007.03.028

Salo, A.; Gustafsson, T.; Ramanathan, R. 2003. Multi-criteria methods for technology foresight, Journal of Forecasting 22(2-3): 235-255. http://dx.doi.org/10.1002/for.850

Scott, J. A.; Ho, W.; Dey, P. K. 2012. A review of multi-criteria decision-making methods for bioenergy systems, Energy 42(1): 146-156. http://dx.doi.org/10.1016/j.energy.2012.03.074

Tadic, S. R.; Zecevic, S. M.; Krstic, M. D. 2014. Ranking of logistics system scenarios for central business district, Promet - Traffic \& Transportation 26(2): 159-167.

Teng, D. 2011. Topsis method for dynamic evaluation of hi-tech enterprises strategic performance with intuitionistic fuzzy information, Advances in Information Sciences and Service Sciences 3(11): 443-449. http://dx.doi.org/10.4156/aiss.vol3.issue11.55

Trutnevyte, E.; Stauffacher, M.; Scholz, R. W. 2012. Linking stakeholder visions with resource allocation scenarios and multi-criteria assessment, European Journal of Operational Research 219(3): 762-772. http://dx.doi.org/10.1016/j.ejor.2012.01.009

Wang, J. Q.; Zhang, H. Y.; Ren, S. C. 2013. Grey stochastic multi-criteria decision-making approach based on expected probability degree, Scientia Iranica E20(3): 873-878.

Wang, Y.; Shi, X.; Sun, J.; Qian, W. 2014. A grey interval relational degree-based dynamic multi-attribute decision making method and its application in investment decision making, Mathematical Problems in Engineering, Article ID 607016, 1-6.

$\mathrm{Xu}, \mathrm{Z}$. 2008. On multi-period multi-attribute decision making, Knowledge-Based Systems 21(2): 164171. http://dx.doi.org/10.1016/j.knosys.2007.05.007

Xu, Z.; Yager, R. 2008. Dynamic intuitionistic fuzzy multi-attribute decision making, International Journal of Approximate Reasoning 48(1): 246-262. http://dx.doi.org/10.1016/j.ijar.2007.08.008

Yao, S. 2010. A distance method for multi-period fuzzy multi-attribute decision making, International Conference on E-Product E-Service and E-Entertainment (ICEEE), 7-9 November 2010, Henan, 1-4.

Zavadskas, E. K.; Kaklauskas, A. 1996. Determination of an efficient contractor by using the new method of multicriteria assessment, in D. A. Langford, A. Retik (Eds.). International Symposium for "The Organisation and Management of Construction". Shaping Theory and Practice 2: Managing 
the Construction Project and Managing Risk. CIB W 65; London, Weinheim, New York, Tokyo, Melbourne, Madras. - London: E and FN SPON, 94-104.

Zavadskas, E. K.; Turskis, Z. 2010. A new additive ratio assessment (ARAS) method in multicriteria decision-making, Technological and Economic Development of Economy 16(2): 159-172. http://dx.doi.org/10.3846/tede.2010.10

Zavadskas, E. K.; Turskis, Z. 2011. Multiple criteria decision making (MCDM) methods in economics: an overview, Technological and Economic Development of Economy 17(2): 397-427. http://dx.doi.org/10.3846/20294913.2011.593291

Zavadskas, E. K.; Turskis, Z.; Antucheviciene, J.; Zakarevicius, A. 2012. Optimization of weighted aggregated sum product assessment, Electronics and Electrical Engineering (6): 3-6.

Zavadskas, E. K.; Turskis, Z.; Kildiene, S. 2014. State of art surveys of overviews on MCDM/MADM methods, Technological and Economic Development of Economy 20(1): 165-179. http://dx.doi.org/10.3846/20294913.2014.892037

Zhang, Z. 2012. An approach to dynamic multi-attribute decision making for choosing green supplier, Journal of Convergence Information Technology 7(21): 261-269. http://dx.doi.org/10.4156/jcit.vol7.issue21.33

Zulueta, Y.; Martínez-Moreno, J.; Martínez, L.; Espinilla, M. 2013. A discriminative dynamic index based on bipolar aggregation operators for supporting dynamic multi-criteria decision making, Advances in Intelligent Systems and Computing 228: 237-248.

http://dx.doi.org/10.1007/978-3-642-39165-1_25

Sarfaraz HASHEMKHANI ZOLFANI is PhD candidate of Technology Foresight in Amirkabir University of Technology (Tehran Polytechnic). He is in cooperating with Futures Studies Research Institute of Amirkabir University of Technology (Tehran Polytechnic) and Sustainability office of Amirkabir University of Technology (Tehran Polytechnic). He is part time research associate in council for futures studies, Iranian Academy of Sciences and adviser to the president, Iranian Society of Future Studies. $\mathrm{He}$ is Council member of International Association of Grey System and Uncertain Analysis (GSUA) and member of EURO Working Group OR in Sustainable Development and Civil Engineering. He is reviewer in journals like: Technological and Economic Development of Economy, Technological Forecasting and Social Change, Evaluation and Program Planning, Journal of Business Economics and Management, International Journal of Strategic Property Management, and etc. He is author of more than 50 scientific papers that presented, published or reviewed at/for International Conferences and Journals (including ISI-cited publications). He has published in journals such as: Expert Systems with Applications, Energy Conversion and Management, Technological and Economic Development of Economy, Journal of Business Economics and Management, International Journal of Strategic Property Management, Archives of Civil and Mechanical Engineering, and etc. His research interests include: Performance Evaluation, Strategic Management, Decision-making Theory, Supply Chain Management, (Dynamic/Prospective) Multi Criteria Decision Making, Future Studies, Sustainable Development and Game Theory.

Reza MAKNOON is faculty member of Civil and Environmental Engineering Department of Amirkabir University of Technology (Tehran Polytechnic) since 1977. He got PhD in Environmental Engineering from University of Washington in 1977. He is president of Iranian Water Resource Association and ex-president of Society for Science Development in Iran and also vice president of Iranian Society of Environmentalists. He is member and past president of Iranian National Committee on Hydrology (IHP) and also Iranian Committee on Large Dams. He is chairperson of Iranian National Committee for Sustainable Development (CSD) since 1995 in Iran. He is author of more than 70 research articles in sustainable tourism, water resource developments, environmental impact assessments, research policies and human development and higher education fields. He is editorial board of Environmental Studies (Quarterly Journal) of Iran. 
Edmundas Kazimieras ZAVADSKAS. PhD, DSc, h.c.multi. Prof., the Head of the Department of Construction Technology and Management at Vilnius Gediminas Technical University, Lithuania. Senior Research Fellow at the Research Institute of Smart Building Technologies. PhD in Building Structures (1973). DrSc in Building Technology and Management (1987). A member of Lithuanian and several foreign Academies of Sciences. Doctore Honoris Causa from Poznan, Saint Petersburg and Kiev universities. Honorary International Chair Professor of the National Taipei University of Technology. A member of international organizations; a member of steering and programme committees at many international conferences; a member of the editorial boards of several research journals; the author and co-author of more than 400 papers and a number of monographs in Lithuanian, English, German and Russian. The editor-in-chief of journals Technological and Economic Development of Economy and Journal of Civil Engineering and Management. Research interests: building technology and management, decision-making theory, automation in design and decision support systems. 